\title{
Entre recursos táteis e audiodescritivos: a construção de um discurso para atribuir acessibilidade à fotografia
}

\author{
Between tactile and audio descriptive resources: the construction of a speech to assign accessibility to photography \\ - Adriane Borda \\ GEGRADI, FAURB, UFPel, Brasil \\ adribord@hotmail.com \\ - Monica Veiga \\ GEGRADI, FAURB, UFPel, Brasil \\ veiga.monicam@gmail.com \\ - Larissa Dall'Agnol da Silva \\ FM, UFPel, Brasil \\ larissadallagnolto@gmail.com \\ - Francisca Michelon \\ ICH, UFPel, Brasil \\ fmichelon.ufpel@gmail.com \\ - Desirée Salasar \\ FM, UFPel, Brasil \\ dedah.nobres@gmail.com
}

\begin{abstract}
This paper presents a study of integrating assistive resources for the field of observation and experimentation of a photographic exhibition in order to receive the visually impaired. The exhibition applied the concept of Universal Design as the axis of a transverse and interdisciplinary methodology in order to propose communication and mediation welcoming solutions and research likely to qualify inclusive museological spaces. This study evaluates the potential integration of accessibility features to create an enabling environment of access to knowledge and culture. The resources were developed in four projects: expography; production of threedimensional tactile models and schemes; accessible mediation and audio description.
\end{abstract}

Keywords: Photography, Tactile Resources, Audio Description, Accessible Mediation

\section{Introdução}

Este texto apresenta um estudo de integração de recursos assistivos tendo como campo de observação e experimentação uma exposição fotográfica objetivada à recepção de pessoas com deficiência visual. A exposição foi desenhada em um Programa de Extensão - o Museu do Conhecimento para todos - e empregou o conceito do Desenho Universal como o eixo de uma metodologia transversal e interdisciplinar para propor soluções de recepção, comunicação, mediação e pesquisa passíveis de qualificar os espaços museais inclusivos. Avaliase o potencial da integração dos recursos de acessibilidade na geração de um ambiente facilitador do acesso ao conhecimento e à cultura. O programa no qual se desenvolve a experiência relatada, interdisciplinar na origem, envolve recursos humanos e materiais de sete cursos de Bacharelado (Arquitetura e Urbanismo, Museologia, Conservação e Restauro, Terapia Ocupacional, Cinema, Design Gráfico e Design Digital) e de dois programas de pós-graduação (de Arquitetura e Urbanismo e de Memória Social e Patrimônio Cultural), todos da Universidade Federal de Pelotas e tem na Escola Louis Braille e no Centro de Reabilitação Visual, ambos situados na cidade de Pelotas, Rio Grande do Sul, os parceiros na sua formulação, na proposição de metodologias e na avaliação dos resultados. Os recursos foram desenvolvidos em quatro projetos: 1. expografia; 2. produção de esquemas tridimensionais e maquetes táteis, 3. mediação acessível e 4. audiodescrição.

\section{Materiais e Métodos}

No museu, têm sido frequentes os exemplos que tornam os recursos assistivos um atrativo, para qualquer visitante. Há muitas soluções: esquemas visuais, maquetes para tocar, obras disponíveis ao toque, leitura fácil em legendas e folders, áreas de descanso, audiodescrição, mediação acessível e outros. No entanto, a integração depende do nível da proposta de acessibilidade. Na experiência que se relata, é o Desenho Universal que regimenta o projeto de ocupação de um espaço expositivo. Os recursos empregados se encontram na audiodescrição de fotografias, na leitura fácil, na produção de esquemas e maquetes táteis e na recepção e acompanhamento de visitantes. Em todos, de modo e em proporção diversa, foram empregados os sete princípios do Desenho Universal, a saber: I - uso equitativo; II - uso flexível; III - uso simples e intuitivo; IV - informação de fácil percepção; V - segurança; VI - esforço físico mínimo; VII - dimensionamento para acesso e uso abrangente. (ORNSTEIN, 2010, p. 15-21). Por outro lado, o princípio da universalidade contempla os preceitos enunciados na Lei 10.098/2000, no Decreto 5.296/2004 e no Estatuto dos Museus - Lei 11.094/2009, bem como no conceito de museu universitário (CABRAL, 2002), que entende que a inclusão constrói-se a partir da integração. Esta integração também se oferece por meio dos recursos assistivos comunicacionais, para os quais concorrem os estudos de Neves $(2006,2009)$ aplicados no projeto assistivo do Museu da Comunidade Concelhia da 
Batalha, em Portugal. Advoga-se que os museus "devem ser considerados como lugares de convivência entre pessoas de todos os tipos e inteligências, no legítimo exercício de seus direitos, necessidades e potencialidades" (Fabri, 2010, p.31). Um museu universitário, segundo Cabral (2002, p. 33) deve propor-se a "(...) integrar solidariamente as funções científicodocumentais, educacionais e culturais da Universidade com a marca da ação museal".

O Memorial foi constituído no edifício do Campus Anglo da Universidade Federal de Pelotas, dentro do local onde foram as câmaras frias de um extinto Frigorífico, comprado pela Universidade em 2010 para ser o atual campus. As imagens da figura 1 ilustram as edificações, antes e depois da ocupação pela universidade.

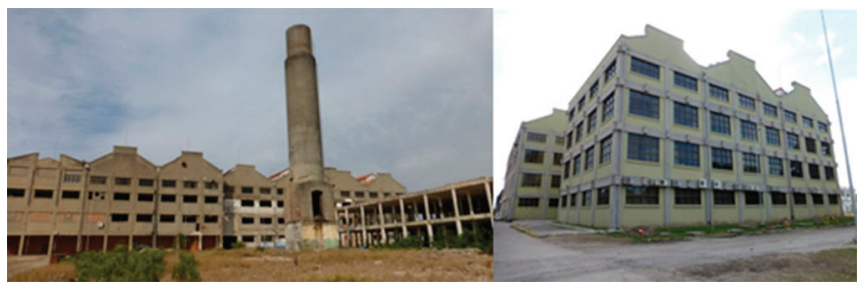

Figura 1: fotos de antes e depois da aquisição do local do frigorifico pela UFPel. Fonte: fotos de Ubirajara Cruz, coleção do Memorial.

O primeiro projeto que viabilizou a constituição do memorial ajustou o lugar ocupando-o com mobiliário expositivo e ambientação específica, ilustrados pela figura 2.

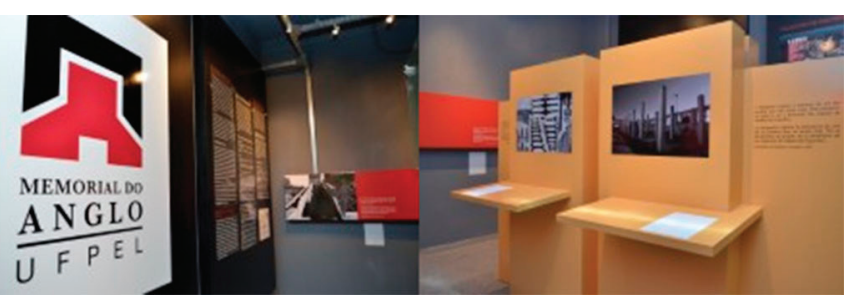

Figura 2: fotografias do ambiente do memorial. Fonte: autoras.

No segundo projeto desenvolveram-se os esquemas e maquetes de 5 das 13 fotografias expostas, além de disponibilizar uma maquete do conjunto das edificações (figura 3).

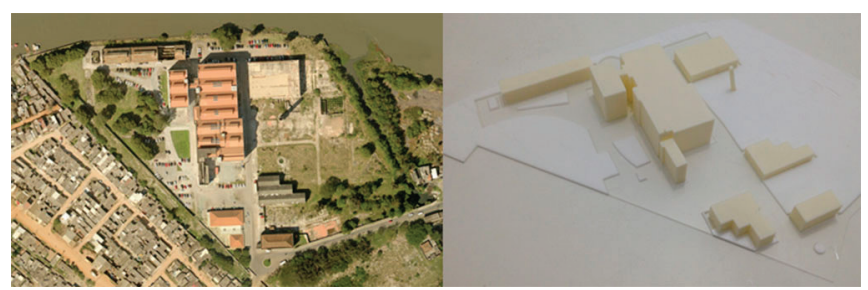

Figura 3: foto aérea do Campus Anglo da UFPel e maquete tátil das edificações que compõem o local. Fonte: foto aérea cedida pela Prefeitura Municipal de Pelotas.
No terceiro projeto produziram-se as audiodescrições de toda a exposição, descrevendo o ambiente e as fotografias. No quarto projeto, desenvolveu-se o treinamento da mediação. No site do Memorial do Anglo (www.memorialdoanglo.com. $\mathrm{br} /$ ) constam fotos do resultado geral.

A figura 4 traz o registro de um momento de visitação, podendo-se observar o uso de recurso auditivo e o tipo de maquete e esquema tátil que acompanha a fotografia que está sendo descrita. A integração durante a visita é dada pela mediação que tanto conduz o visitante como potencializa o uso deste conjunto de recursos, reforçando o vínculo com a descrição da imagem.

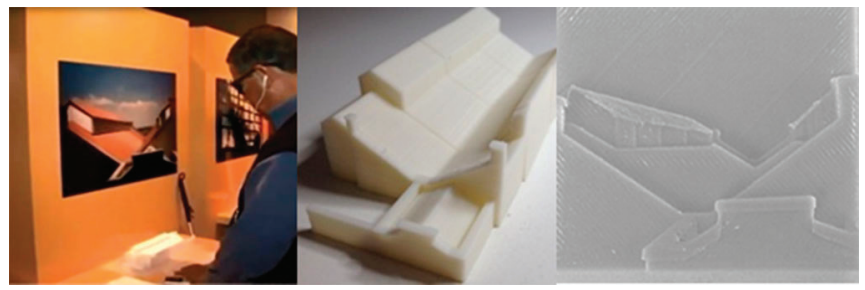

Figura 4: na sequencia, registro de um momento de apreciação da fotografia de telhados (foto de Ubirajara Cruz); maquete e esquema táteis associados à fotografia. Fonte: autoras.

As figuras 5, 6 e 7, demonstram as especificidades dos esquemas e maquetes associados a cada fotografia.

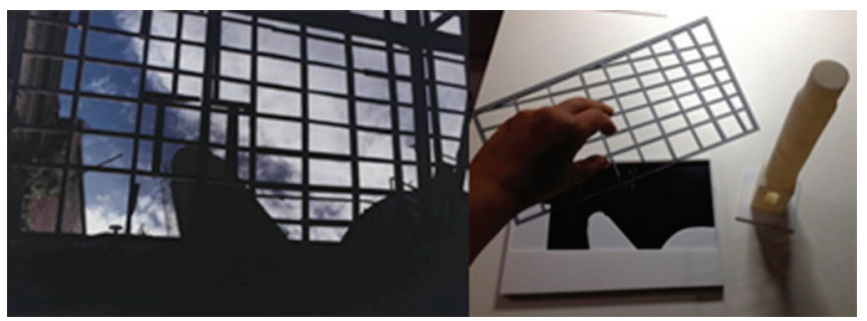

Figura 5: fotografia de uma chaminé através da janela. Ao lado os esquemas e a maquete para subsidiar a mediação. Fonte: foto de Francisca Michelon, coleção do Memorial.

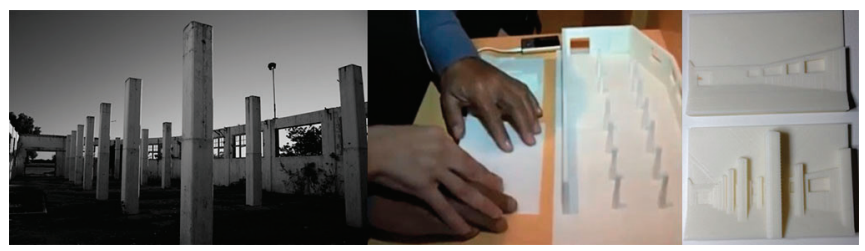

Figura 6: na sequencia, fotografia dos pilares, registro de um momento da apreciação da fotografia, esquemas complementares. Fonte: foto de Gilberto Carvalho, coleção do Memorial. 


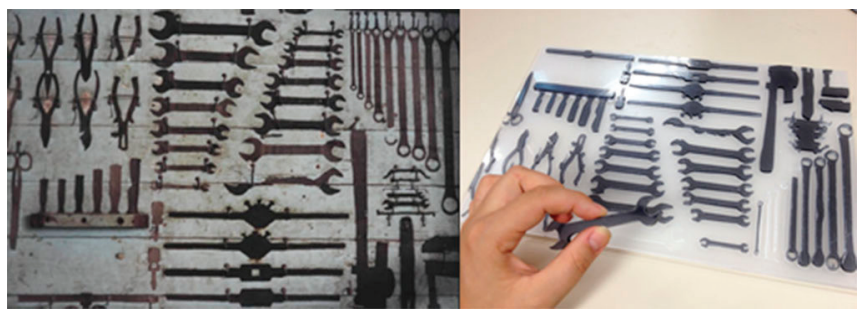

Figura 6: na sequencia, fotografia dos pilares, registro de um momento da apreciação da fotografia, esquemas complementares. Fonte: foto de Gilberto Carvalho, coleção do Memorial.

\section{Resultados}

Uma vez implantada a exposição e incluídos os recursos, passou-se à avaliação que se deu através de instrumentos usuais em pesquisa de público em museus. O sistema de avaliação dividiu-se em três etapas. A primeira foi a avaliação feita pelos consultores de todos os itens do projeto. Os consultores foram os professores da Escola Louis Braille, videntes e cegos.

A segunda etapa foi a avaliação do rendimento dos recursos feita por visitantes videntes com vendas e sem vendas. A terceira foi a avaliação feita pelo público alvo através de instrumentos específicos (entrevistas, fichas de avaliação de exposição, coleta de dados através dos parceiros) após a visitação. Os dados obtidos estão sendo tabulados conforme critérios estabelecidos no diagnóstico e nos pareceres dos consultores. Aplica-se aos produtos e aos resultados das exposições. Sobretudo, a relação entre as representações táteis e a audiodescrição foram abordadas na sua eficácia quanto a informar ao visitante o conteúdo da imagem.

Neste sentido, destaca-se que os estudos para a produção dos esquemas tridimensionais e maquetes táteis fundamentam-se no experimento de materiais, cor, textura e dimensões, incluindo a localização do Memorial e de detalhes das fotografias. O resultado deste estudo da tradução da informação em suporte visual para esquemas com volumes e proporções foi a produção de dois a três esquemas e/ ou maquetes por fotografia, nas quais ponto de vista, perspectiva e relação entre os elementos foram apresentados tridimensionalmente.

$\mathrm{Na}$ audiodescrição, outros elementos foram focalizados seguindo um princípio geral de apresentação de contexto para detalhamento dos elementos. Cada audio foi limitado em dois minutos ou menos de texto lido. O primeiro item foi a descrição do objeto em si (exemplo: fotografia em cor ou fotografia em preto e branco), o segundo item já descrevia o conteúdo geral da imagem (exemplo: "do frontão do prédio das conservas..."). Buscou-se a relação entre o conteúdo descrito da imagem e os principais aspectos que geraram os esquemas ou as maquetes.

No entanto, foi a mediação que tornou possível integrar os dois recursos. A condução das mãos do visitante sobre as maquetes, a eleição da primeira maquete e a sucessão das demais, a apresentação da imagem antes do toque foi um sistema de apresentação sequencial das traduções do conteúdo visual nos dois recursos apresentados.

\section{Discussão}

A inclusão é um resultado multifatorial que ocorre progressivamente a partir da eliminação de barreiras. $\mathrm{Na}$ proposta relatada, todos os elementos são tratados à luz de uma ferramenta conceitual: o Desenho Universal (ORNSTEIN, 2010) que nesta experiência transcende o uso corrente na construção civil e nos projetos de design. O forte apelo inclusivo deste conceito levou-o a ser discutido no meio acadêmico quanto a sua aplicação como um princípio. Frequentemente vê-se que o Desenho Universal tratado como uma metodologia para conceber projetos assistivos. O histórico informa que o conceito surge como resposta a reivindicações de dois segmentos sociais: das pessoas com deficiência e de profissionais como arquitetos, engenheiros, urbanistas e designers que entendiam necessária uma visão mais democrática do uso do espaço, que se expressasse desde o projeto. O fundamento básico da ideia era a universalidade e, para tanto, o projeto deveria buscar a solução projetual de modo amplo. A aplicação do conceito nos recursos do Memorial do Anglo partiu de algumas considerações contextuais: 1. De que o contexto da acessibilidade no Brasil dá-se, na expressão das políticas de Estado, por meio de Leis e Decretos, na expressão social como resposta a essa legislação e às demandas da sociedade. 2. De uma ideia de ambiente, de ação e de tratamento acessível, nos quais se formalizam os conceitos de inclusão. 3. De que a acessibilidade constitui a expressão dos meios para que ocorra a inclusão. Estas três considerações firmaram-se no pressuposto de que: o museu contemporâneo, por ser uma instituição com possibilidades experimentais, oferece disposição em se apresentar como um ambiente de notável caráter inclusivo. $\mathrm{O}$ museu, para além da sua já reconhecida função pedagógica e por seu inerente caráter lúdico, é capaz de incorporar, rapidamente, a meta da hospitalidade.

\section{Considerações Finais}

A construção de um discurso para atribuir acessibilidade à fotografia está sendo possível por meio de uma ação interdisciplinar e participativa.

Os recursos acessíveis, disponíveis para todos, apresentam-se como recursos universais que agregam à exposição outros valores, tornando-a potencialmente inclusiva

\section{Agradecimentos}

Agradecemos aos dirigentes das instituições envolvidas neste trabalho, da Escola Louis Braille e do Centro de Reabilitação Visual da cidade de Pelotas e, especialmente, à comunidade que participou dos experimentos. 


\section{Referências}

CABRAL, M. Museu: pesquisa e documentação. In: Seminário sobre Museus-casa: pesquisa e documentação. n. 4, 2002, Rio de Janeiro. Anais Museus-casas: pesquisa e documentação. Rio de Janeiro. Fundação Casa de Rui Barbosa, 2002, p. 9-10.

FABRI, Angélica. Acessibilidade: a ampliação do papel social do Museu Casa de Portinari. In Caderno de Acessibilidade, reflexões e experiências em exposições e museus. São Paulo: Expomus, 2010.

NEVES, J. Museus Acessíveis... museus para todos?! Comunicação apresentada no Congresso de Turismo Cultural, Territórios e Identidade. Projecto de Investigação Identidade(s) e Diversidade(s). Escola Superior de Educação do Instituto Politécnico de Leiria. Leiria, 29-30 Outubro 2006.

NEVES, J. Cinema inclusivo: soluções diferenciadas para uma comunicação mais abrangente. Revista Diversidades, 24. Região Autónoma da Madeira: Secretaria Regional de Educação e Cultura

/ Direcção Regional de Educação Especial e Reabilitação / Direcção de Serviços de Apoio,

Gestão de Recursos e Investigação. 2009. pp.22-24.

ORNSTEIN, S.W. (org.). Desenho universal: caminhos da acessibilidade no Brasil. São Paulo: Annablume, 2010.

BRASIL. Leis $n^{\circ} 10.048$, de 8 de novembro de 2000, que dá prioridade de atendimento às pessoas com deficiência. Diário Oficial [da]República Federativa do Brasil, Brasília, DF, 2000.

BRASIL. Leis $n^{\circ}$ 10.098, de 19 de dezembro de 2000, que estabelece normas gerais e critérios básicos para a promoção da acessibilidade. Diário Oficial [da]República Federativa do Brasil, Brasília, DF, 2000.

BRASIL. Decreto-lei 5.296 de 2 de dezembro de 2004. Regulamenta as Leis $n^{\circ}$ s 10.048 , de 8 de novembro de 2000, que dá prioridade de atendimento às pessoas que especifica, e 10.098, de 19 de dezembro de 2000, que estabelece normas gerais e critérios básicos para a promoção da acessibilidade. Diário Oficial [da]República Federativa do Brasil, Brasília, DF, 2004.

BRASIL. Lei no 11.904 de 14 de janeiro de 2009. Estabelece o estatudo dos Museus. Diário Oficial [da]República Federativa do Brasil, Brasília, DF, 15/01/2009.

BRASIL. Decreto do Executivo no 8.124 de 17 de outubro de 2013. REGULAMENTA DISPOSITIVOS DA LEI No 11.904. Diário Oficial [da]República Federativa do Brasil, Brasília, DF, 18/10/2013, p.1.BRASIL 